\title{
ESQUEMAS ARGUMENTATIVOS DE WALTON NA ANÁLISE DE ARGUMENTOS DE PROFESSORES DE QUÍMICA EM FORMAÇÃO INICIAL
}

\author{
Marina Martins* \\ Stefannie de Sá lbraim** \\ Paula Cristina Cardoso Mendonça ${ }^{* *}$
}

RESUMO: Utilizamos os 60 Esquemas Argumentativos de Walton (EAW) para analisar, reconstruir e classificar argumentos de professoras de Química em formação inicial em situação de entrevista sobre dois problemas: i) derretimento de bonecos de neve (SP1); ii) fenômeno da queima de uma vela (SP2). Ambos favorecem a mobilização de argumentos envolvendo uso de conceitos científicos, sendo estes, em SP1, mudanças de estado físico e fenômenos de absorção e reflexão da luz e, em SP2, reações químicas. Cada problema demandava dos sujeitos habilidades distintas para análise de evidências, proposição de justificativas e elaboração de conclusões. Houve predomínio de esquemas relacionados ao raciocínio científico - o que indica que as licenciandas manifestaram tal forma de pensar, algo relevante para situações em sala de aula - e número similar de argumentos nos dois problemas. Percebemos que os tipos de EAW mobilizados pelas licenciandas foram influenciados pela natureza dos problemas e pelos conhecimentos científicos envolvidos nas resoluções.

Palavras-chave: Esquemas argumentativos. Professores de química em formação inicial. Walton.

\section{ESQUEMAS ARGUMENTATIVOS DE WALTON EN EL ANÁLISIS DE ARGUMENTOS DE PROFESORES DE QUÍMICA EN FORMACIÓN INICIAL}

RESUMEN: Utilizamos los 60 Esquemas Argumentativos de Walton (EAW) para analizar, reconstruir y clasificar argumentos de profesoras de química en formación inicial en situación de entrevista acerca dos problemas: i) derretimiento de muñecos de nieve (SP1); ii) la queima de una vela (SP2). Ambos favorecen la movilización de argumentos que usan conceptos científicos: en SP1 el cámbio de estado físico y fenómenos de absorción de luz y en SP2 reacciones químicas. Cada problema demandava de los sujetos habilidades distintas para análisis de evidéncias, proposición de justificativas y elaboración de conclusiones. Hubo predomínio de esquemas relaccionados al raciocínio científico - qué indica que las licenciadas manifestaron tal forma de pensar, algo relevante para el aula - y número similar de argumentos en los dos problemas. Percibimos que los tipos de EAW movilizados por las

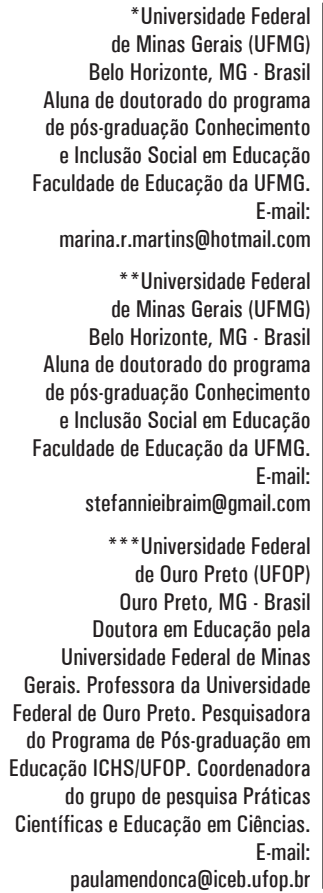

*Universidade Federal de Minas Gerais (UFMG) Belo Horizonte, MG - Brasil Aluna de doutorado do programa de pós-graduação Conhecimento e Inclusão Social em Educação Faculdade de Educação da UFMG. E-mail:

marina.r.martins@hotmail.com

* *Universidade Federal de Minas Gerais (UFMG)

Belo Horizonte, MG - Brasil Aluna de doutorado do programa de pós-graduação Conhecimento e Inclusão Social em Educação Faculdade de Educação da UFMG. E-mail: stefannieibraim@gmail.com

***Universidade Federal de Ouro Preto (UFOP) Ouro Preto, MG - Brasil Doutora em Educação pela Universidade Federal de Minas Gerais. Professora da Universidade Federal de Ouro Preto. Pesquisadora do Programa de Pós-graduação em Educação ICHS/UFOP. Coordenadora do grupo de pesquisa Práticas Científicas e Educação em Ciências. E-mail: paulamendonca@iceb.ufop.br 
licenciadas fueron influenciados por la naturaleza de los problemas y por los conocimientos científicos de las resoluciones.

Palabras clave: Esquemas argumentativos. Profesores que química en formación inicial. Walton.

ANALIZING PRE-SERVICE CHEMESTRY TEACHERS' ARGUMENTS USING WALTON'S ARGUMENTATIVE SCHEMES

ABSTRACT: We used Walton's 60 Argumentative Schemes (WAS) to analyse pre-service chemistry teacher's arguments in an interview about two problems: i) snowmen melting (SP1); and ii) a burning candle (SP2). Both problems favour arguments mobilization involving scientific concepts' use. SP1 favours knowledge related to physical state changes and absorption and reflection of light, while SP2 involves chemical reactions. The problems demanded distinct skills from the pre-service chemistry teachers, regarding the analysis of evidence, proposing justifications and drawing conclusions. We found a predominance of schemes related to scientific reasoning and similar arguments in the two problems - which indicates that teachers had developed such ways of thinking, which may be relevant to classroom situations. We realised that the WAS kinds mobilized by the pre-service teachers are influenced by the nature of the problems and the scientific knowledge involved in the resolutions.

Keywords: Argumentation Schemes. Pre-service chemistry teachers. Walton. 


\section{INTRODUÇÃO}

Nos últimos 20 anos, tem sido crescente o número de pesquisas relacionadas à temática "argumentação" no ensino de ciências (por exemplo, MENDONÇA; JUSTI, 2013a; DRIVER; NEWTON; OSBORNE, 2000; DUSCHL; OSBORNE, 2002; ERDURAN; JIMÉNEZ-ALEIXANDRE, 2008). Várias publicações nacionais e internacionais estão preocupadas em (i) compreender as condições e as estratégias para o desenvolvimento da argumentação (socio)científica de estudantes dos diversos níveis educacionais (por exemplo, MENDONÇA; JUSTI, 2014; CARMO; CARVALHO, 2012; GARCIA-MILA; ANDERSENG, 2008; KOSLO; RATCLIFFE, 2008;); (ii) promover a formação de professores de ciências de forma a atender às demandas atuais de uma educação em ciências voltada para a formação de cidadãos críticos (por exemplo, SÁ; QUEIROZ, 2007; SIMON; JOHNSON, 2008; ZEMBAUL-SAUL; MUNFORD; CRAWFORD; FRIEDRICHSEN, 2002) e (iii) avaliar ferramentas metodológicas a partir da análise dos argumentos produzidos por estudantes e professores e da evolução de suas capacidades argumentativas (por exemplo, ANTHONY; KIM, 2015; IBRAIM; MENDONÇA; JUSTI, 2013; SAMPSON; CLARK, 2008).

Considerando essas vertentes de pesquisa em argumentação, este trabalho visa contribuir para as discussões relacionadas à avaliação de ferramentas metodológicas. As discussões sobre como avaliar a qualidade da argumentação de estudantes e professores de ciências, tanto em situações de discussões orais em grupos de estudantes quanto com toda a classe ou em argumentos escritos (por exemplo, ANTHONY; KIM, 2015; KONSTANTINIDOU; MACAGNO, 2013; SAMPSON; CLARK, 2008; SASSERON; CARVALHO, 2011) têm sido constantes na comunidade de pesquisadores. Mais especificamente, têm sido dirigidas críticas ao uso do padrão analítico de Toulmin (conhecido como TAP ${ }^{1}$ ) para análise de argumentos (para mais detalhes, consultar IBRAIM et al., 2013; DUSCHL, 2008; NIELSEN, 2013) e têm sido produzidas versões modificadas de tal padrão (JIMÉNEZ-ALEIXANDRE; BUGALLO RODRÍGUES; OSBORNE, 2000; OSBORNE; ERDURAN; SIMON, 2004; ZOHAR; NEMET, 2002) ou instrumentos mais específicos aos casos investigados e ao contexto do ensino de ciências para análise de argumentos (ABI-EL-MONA; ABD-EL-KHALICK, 2011; MENDONÇA; JUSTI, 2014; SANDOVAL; MILLWOOD, 2008).

Os esquemas argumentativos de Walton e seus colaboradores (WALTON; REED; MACAGNO, 2008) (aqui designados por EAW) têm se mostrado como uma possibilidade para analisar argumentos, porque neles o foco é dirigido às inferências envolvidas nos raciocínios dos indivíduos que argumentam, e não à estrutura dos argumentos como, por exemplo, no TAP (ANTHONY; KIM, 2015; IBRAIM et al., 2013; DUSCHL, 2008; KONSTANTINIDOU; MACAGNO, 2013; OZDEM; ERTEPINAR; CAKIROGLU; ERDURAN, 2011). Todavia, existem poucos relatos de pesquisas que têm utilizado as ideias de Walton e seus colaboradores na análise de argumentos de estudantes e professores no âmbito do ensino de ciências, principalmente no contexto brasileiro. Em um trabalho anterior, Ibraim et al. (2013) utilizaram os $60 \mathrm{EAW}$, que foram traduzidos, exemplificados e agrupados em classes similares pelas autoras, para analisar 
argumentos de estudantes de química do Ensino Médio que foram entrevistados sobre questões-problema de duas naturezas (envolvendo conhecimentos científicos e do cotidiano). Nesse trabalho, as autoras apresentaram várias implicações sobre o uso dos EAW, entre as quais, a relevância de usá-los para avaliar a argumentação de professores de ciências. No presente artigo, temos como objetivo utilizar os 60 EAW para analisar argumentos de professores de química em formação inicial que foram entrevistados sobre problemas de cunho científico e discutir tal análise à luz da literatura contemporânea.

\section{OS ESQUEMAS ARGUMENTATIVOS DE WALTON E COLABORADORES E SEUS USOS EM PESQUISAS DA ÁREA DE ENSINO DE CIÊNCIAS}

De acordo com Wenzel (1990), a argumentação pode ser entendida a partir de três perspectivas: retórica, dialética e lógica. De forma simplificada, a perspectiva retórica envolve a produção de um discurso, podendo ser escrito ou falado, em que o argumento é utilizado para resolver problemas e tomar decisões. De forma geral, o propósito principal da retórica é a persuasão, empregada na escolha entre alternativas que apresentam boas razões em ambos os lados. Por outro lado, a dialética consiste na organização sistemática de uma interação, por exemplo, debates e discussões, no intuito de produzir melhores decisões. Em outras palavras, a dialética enfatiza o procedimento envolvido na construção de um argumento e o contexto dessa produção (MENDONÇA; JUSTI, 2013b). Nesse sentido, a perspectiva dialética enfatiza a ideia de plausibilidade associada à proposição de argumentos, o que significa, na prática, que a aceitação de um argumento poderá ser determinada a partir de critérios estabelecidos pelos sujeitos envolvidos nos processos argumentativos (RIGOTTI; MORASSO, 2009). Por fim, na perspectiva lógica, a argumentação se destina à produção de proposições destinadas a apoiar uma conclusão, e um bom argumento é constituído por uma afirmativa sustentada por evidência(s) e justificativa(s).

Em relação à lógica, esta se desdobra em dois grupos: a lógica formal e a lógica informal. A lógica formal tem como objetivo elaborar meios para assegurar que nosso pensamento proceda de forma correta a fim de chegar a conhecimentos verdadeiros. Nesse tipo de lógica, os raciocínios presentes são o dedutivo e o indutivo. Este último estabelece generalizações, isto é, cria proposições universais a partir de proposições particulares. No raciocínio dedutivo, o argumento parte de uma proposição geral (referente a todos os elementos de um conjunto) e conclui com uma proposição particular (referente à parte dos elementos de um conjunto), que se apresenta como necessária, ou seja, que deriva logicamente das premissas. A construção de argumentos que envolvem esses raciocínios é realizada a partir de silogismos. Silogismos são construções lógicas compostas por premissas maiores e menores que levam à dedução de uma conclusão ${ }^{2}$ (WENZEL, 1990). Contudo, essa perspectiva formal apresenta alguns problemas quando passamos a considerar não apenas argumentos exemplares, mas, por exemplo, a analisar a argumentação cotidiana, isto porque essa estrutura de argumentação não representa a variedade de possibilidades de argumentos. Além disso, as construções silogísticas podem originar uma conclusão inadequada ${ }^{3}$ (RIGOT'TI; MORASSO, 2009). 
Somado a isso, os lógicos formais não reconhecem argumentos que recorrem, por exemplo, ao apelo emocional ou de especialistas e ao caráter do sujeito. Para os lógicos formais, os últimos argumentos especificados são tidos como falácias, uma vez que apresentam conclusões e premissas possíveis de serem falseadas. Em contrapartida, alguns pesquisadores do campo da argumentação (por exemplo, TOULMIN, 1958; WALTON, 1996; WALTON et al., 2008; VAN EEMEREN et al., 1996) reconhecem que esses tipos de argumentos caracterizam bem o nosso contexto real, como discussões cotidianas, políticas, científicas, midiáticas, do campo do direito etc.

A perspectiva da lógica informal teve como início a necessidade de buscar substituir os exemplos artificiais que caracterizavam os bons e maus argumentos nos textos de lógica. Essa perspectiva buscou analisar exemplos de argumentos retirados do contexto cotidiano e compreender os processos argumentativos presentes (GROARKE apud RIGOTTI; MORASSO, 2009). Em termos práticos, a lógica informal tem a finalidade de elaborar procedimentos para análise, interpretação, avaliação, crítica e construção da argumentação no discurso cotidiano (MENDONÇA; JUSTI, 2013b). Assim, na lógica informal, as conclusões são consideradas passíveis de aceitação, isto é, elas não são verdades absolutas, o que implica em poderem ser refutadas frente a novas evidências ou à invalidação das premissas.

Um dos pesquisadores que têm apresentado grandes contribuições para os estudos na perspectiva da lógica informal é Douglas Walton. Esse autor apresenta inúmeras publicações que tratam sobre as falácias, nomeadas também como esquema argumentativo (por exemplo MACAGNO; WALTON; TINDALE, 2014; MACAGNO; WALTON, 2015; WALTON, 1992, 1996, 1999b, 2001, 2002, 2006a, 2006b, 2008, 2009a, 2009b, 2014a, 2014b; WALTON; MACAGNO, 2009; WALTON; MACAGNO, 2015; WALTON; REED, MACAGNO, 2008). Dentre as obras desse autor, as mais referenciadas são: Walton (1996) e Walton et al. (2008). Naquela, Walton propôs 25 esquemas argumentativos como formas de argumentos (padrões de diálogos ou formas abstratas de raciocínio) utilizados no discurso do dia a dia e em contextos específicos, como argumentação no campo científico e no direito. Esses esquemas se fundamentam, principalmente, no raciocínio presuntivo, isto é, aquele que apoia inferências em condições de incompletudes e permite que dados desconhecidos sejam presumidos. Em 2008, Walton e colaboradores (WALTON et al., 2008) escreveram o livro "Argumentation Schemes", no qual incorporaram outros esquemas, resultando em um total de 60. Alguns desses novos esquemas apresentam outro tipo de raciocínio, o falseável, que é aquele no qual a conclusão pode ser retirada a partir de um conjunto de dados conhecidos (mas incertos), porém, esta pode ser modificada ou abandonada caso esses dados não sejam mais válidos ou adequados. Tanto o raciocínio presuntivo quanto o falseável se fundamentam na ideia de plausibilidade, segundo a qual, se as premissas são plausíveis de serem aceitas, a conclusão é tão plausível quanto as premissas. Portanto, podemos inferir que os raciocínios presuntivo e falseável podem não ser fortes por si só, mas podem ser fortes o suficiente para fornecer evidências para justificar racionalmente a aceitabilidade de suas conclusões (TOULMIN, 1958). 
Para investigar a qualidade de um esquema argumentativo produzido em contexto dialógico, Walton et al. (2008) propuseram um conjunto de questões críticas para avaliar cada esquema argumentativo. Assim, para esses autores, a estrutura de argumentação presuntiva consiste no relacionamento entre esquemas e questões críticas, e há a consideração do contexto para se avaliar um argumento como forte ou fraco. Julgamos esse aspecto essencial para a análise de argumentos no Ensino de Ciências, uma vez que a literatura tem apontado que a análise do contexto contribui para o entendimento de como os indivíduos desenvolvem seus raciocínios argumentativos para dar suporte aos seus pontos de vista (ANTHONY; KIM, 2015). Na opinião de Anthony e Kim (2015), para que tal entendimento seja possível, é necessário recorrer a um referencial analítico que permita uma análise dos aspectos estratégicos e situacionais do episódio argumentativo, em vez de simplesmente analisar os aspectos estruturais dos argumentos.

Um dos pesquisadores pioneiros no uso das ideias de Walton no Ensino de Ciências foi Duschl, que utilizou os EAW (DUSCHL; ELLENBOGEN, 1999) para avaliar a qualidade da argumentação de estudantes que haviam participado do projeto Sepia (cujo objetivo era o desenvolvimento do raciocínio científico). De acordo com esse trabalho, a ferramenta de Walton propiciou uma análise mais detalhada das justificativas em comparação ao TAP, que utiliza categorias muito gerais e abrangentes para caracterizar os argumentos. Os autores utilizaram nove dos 25 esquemas argumentativos propostos por Walton (1996). Segundo eles, os nove esquemas utilizados têm mais relação com o raciocínio científico (sinal, compromisso, opinião de especialista, posição de conbecimento, consequência, analogia, causa para efeito, correlação com causa e evidência para hipótese) e refletem melhor a argumentação que ocorre em salas de aula. Embora Duschl e Ellenbogen (1999) tenham iniciado a análise com nove esquemas, foram constatados problemas de confiabilidade entre árbitros ao tentar diferenciá-los. Com o objetivo de adquirir melhor nível de confiabilidade na análise, os nove esquemas iniciais foram incluídos em quatro categorias de análise: inferência, sinal, compromisso e analogia. Por exemplo, Duschl e Ellenbogen (1999) relataram dificuldades ao diferenciar os esquemas evidência para hipótese, correlação com causa, causa para efeito e consequência, que foram inseridos na categoria "inferência".

Kim, Anthony e Blades (2014) realizaram um estudo com o objetivo de analisara argumentação de professores em formação inicial em casos sociocientíficos utilizando os EAW e levando em consideração a problemática na diferenciação dos esquemas. Para isso, eles se basearam nos nove esquemas selecionados por Duschl e Ellenbogen (1999). Seus resultados reforçaram a posição de Duschl e Ellenbogen quanto à dificuldade de se distinguir determinados esquemas, o que implica a necessidade de tornar o referencial teórico de Walton mais prático para o campo de pesquisas. Em contrapartida, eles discordaram de Duschl e Ellenbogen quanto à inclusão do esquema consequência na categoria "inferência", pois, segundo eles, há distinções entre conceitos causais e de associação. Assim, eles elaboraram uma categoria - correlação - a qual eles incluíram os esquemas de correlação com causa e causa para efeito. Os autores ressaltam a importância de decompor o esquema posição de conhecimento em dois tipos: pessoal e baseado em pesquisas. Isso porque, 
de acordo com Kim, Anthony e Blades (2014), isso poderia contribuir para melhor caracterizar os argumentos desenvolvidos pelos sujeitos. Além disso, os autores apontam que, diferentemente da pesquisa conduzida por Duschl e Ellenbogen (1999), não foi observado nos dados analisados o esquema evidência para hipótese.

Anthony e Kim (2015) também apontaram as dificuldades que eles tiveram em distinguir determinados EAW para avaliar os argumentos orais e escritos de professores em formação inicial em contexto sociocientífico. De acordo com esses autores, as diferenças entre determinados esquemas são sutis. Por exemplo, a descrição do esquema sinal requer a suposição de uma correlação entre algo que é observado e aquilo que é inferido referente ao dado sinal. É a suposição de causalidade que dá sentido ao sinal observado, isto é, do que constitui causa, correlação e previsão. Essa suposição permite que uma simples observação seja classificada como um esquema no qual há mobilização do raciocínio do tipo sinal (ANTHONY; KIM, 2015).

Além disso, Anthony e Kim (2015) propuseram uma tabela na qual listam e comparam os esquemas argumentativos propostos por Walton (1996), aqueles selecionados por Duschl (2008), e os que foram por eles utilizados na análise de dados (KIM; ANTHONY; BLADES, 2014). Os esquemas adaptados pelos autores foram: sinal, compromisso, posição de conhecimento (pessoal e baseados em pesquisas), consequência, analogia, opinião popular, correlação e enviesamento. Esses esquemas apresentam muitas relações com os utilizados por Duschl (2008) em sua análise de dados no contexto do ensino de ciências. Os autores chegaram a um consenso sobre os significados dos esquemas a partir de um processo de análise de dados e por meio de discussões entre árbitros que buscaram ampliar a confiabilidade da análise, tendo em vista a dificuldade de distinção entre os esquemas. Para identificar o tipo de esquema, os autores inferiram premissas implícitas durante as discussões orais a partir de figuras de linguagem ("por exemplo", "por outro lado", "o ponto que quero defender") e do contexto da discussão.

Walton et al. (2008) reconhecem que, por se tratar de 60 esquemas argumentativos, a análise pode ser confusa e gerar dificuldades. Por isso, esses autores propõem um sistema geral de classificação dos esquemas que possibilita incluí-los a partir de características similares. Sendo assim, são propostas três categorias: Argumentos baseados em fontes, Raciocínio e Aplicação de regras para casos. Essas categorias foram recentemente utilizadas por Anthony e Kim (2015), sendo que eles constataram que essa classificação não captura a influência dos valores pessoais e das emoções como elementos da argumentação. Portanto, para eles, torna-se necessário pensar na incorporação de outra dimensão nessa classificação, como raciocínio baseado em valores, porque observaram a existência ou não de valores e fatores interpessoais para mediar escolhas. No trabalho de Ibraim et al. (2013) foi proposta uma classificação dos esquemas diferente daquela de Walton et al. (2008), pois, além das categorias Raciocínio e Regras, os esquemas foram classificados em Conhecimento pessoal e Julgamento de valor. Essas autoras destacaram que em contextos não científicos, principalmente nos que envolvem problemáticas próximas à vivência dos oradores, (por exemplo, o que causa o fracasso escolar), há uma maior expressão de esquemas do tipo Julgamento de valor. Portanto, 
tais autoras endossam a hipótese de Anthony e Kim (2015) ao destacarem a ocorrência de esquemas envolvendo raciocínio baseado em valores.

Tendo em vista as dificuldades de se trabalhar com os 60 EAW, muitos autores (por exemplo, KONSTANDINIDOU; MACAGNO, 2013; OZDEM et al., 2013) têm optado por trabalhar com categorias mais amplas ou com a seleção dos esquemas de acordo com o contexto. Como exemplo, podemos citar o estudo realizado por Konstandinidou e Macagno (2013), que recorreram apenas aos EAW analogia e causa para efeito para identificar as premissas implícitas no desenvolvimento do raciocínio e o conhecimento científico de um problema que envolveu as leis da termodinâmica que fundamentaram os argumentos dos estudantes universitários ao serem questionados sobre o problema dos bonecos de neve (explicar a influência do uso de um casaco preto no derretimento dos bonecos).

Outro aspecto que podemos notar a partir desses estudos é que há frequência de determinados esquemas argumentativos em contexto científico. Por exemplo, Ozdem e colaboradores (2013) notaram que os argumentos mais frequentes durante a seção de experimentação foram de sinal e de correlação com causa enquanto, durante a discussão geral dos experimentos, o esquema evidência para hipótese apareceu com maior frequência. Esses três tipos de argumentos são considerados inerentes ao raciocínio científico (por serem baseados em evidências). A preponderância de EAW dessas naturezas foi percebida também no estudo conduzido por Duschl e Ellenbogen (1999).

\section{QUESTÕES DE PESQUISA}

Como antes discutido, vários trabalhos da área de ensino de ciências têm se preocupado com as questões metodológicas de análise de argumentos, e muitos têm dirigido críticas à análise meramente estrutural dos argumentos. Além disso, existem poucos trabalhos nacionais em que os pesquisadores têm recorrido aos esquemas argumentativos de Walton para análise de argumentos. Em função de tais aspectos, neste artigo, buscamos responder às seguintes questões de pesquisa: Quais EAW podem ser observados a partir dos argumentos produzidos por professores de química em formação inicial em situações de entrevista? O que esses esquemas nos indicam sobre a argumentação desses professores nos contextos científicos investigados? Como os EAW podem ser utilizados para a classificação de argumentos produzidos pelas professoras de química em formação inicial em situações de entrevista? Quais as contribuições de se utilizar os 60 EAW para avaliar os argumentos produzidos pelos professores em formação?

\section{METODOLOGIA}

\section{Coleta de dados}

A coleta de dados foi realizada com uma amostra de alunos do $6^{\circ}$ período do curso de Química Licenciatura (composto por oito períodos) de uma 
universidade federal. A turma era composta por seis professoras em formação, mas apenas cinco participaram da pesquisa, pois uma delas era integrante do projeto de pesquisa que resultou neste artigo. As professoras foram informadas sobre os objetivos da pesquisa e aceitaram participar livremente dela assinando termos de consentimento.

A coleta de dados ocorreu a partir de entrevistas semiestruturadas, que se basearam em dois protocolos apresentados em outros trabalhos (consultar IBRAIM et al., 2013; CORREA, 2011). A primeira situação-problema envolvia o derretimento de bonecos de neve (problema 1) e a outra, o fenômeno de queima de uma vela (problema 2). O problema 1 envolve a apresentação de uma situação em que dois bonecos de neve estão em um mesmo ambiente, a uma mesma temperatura e possuem a mesma massa. Os bonecos se diferem apenas pelo fato de um estar vestido com um casaco (Fred) e de outro não estar (Bob). As licenciandas deveriam escolher e justificar qual dos bonecos de neve iria fundir primeiro. O problema 2 envolve a apresentação de um experimento no qual uma vela é fixada em um recipiente onde é colocada água e, após deixála queimar por um tempo, emborca-se sobre esta um balão volumétrico. As observações obtidas nesse experimento são: a vela apaga, há a formação de bolhas e o nível da água no balão se eleva. Nesse caso, as questões envolvidas se relacionam a cada uma dessas observações, as quais buscamos que as licenciandas justificassem o porquê de elas ocorrerem.

A escolha desses protocolos de entrevistas se deveu aos fatos de: (i) as professoras em formação (possivelmente) apresentarem os conhecimentos prévios necessários para resolvê-los; (ii) os protocolos apresentarem estrutura similar em termos de favorecer situações que contribuem para a elaboração de argumentos de diferentes perspectivas, contra-argumentos e refutações; e (iii) as pesquisadoras terem usado esses protocolos anteriormente em outras pesquisas, o que possibilitaria boa exploração das questões em sua aplicação. Além disso, tendo em vista que o desenvolvimento da argumentação do sujeito pode ser influenciado pelos conhecimentos sobre o assunto (IBRAIM et al., 2013), optamos por utilizar dois protocolos de entrevistas envolvendo problemas científicos diferentes. $\mathrm{O}$ problema 1 favorece a mobilização dos conhecimentos de mudanças de estado físico (fusão) e de fenômenos de absorção e reflexão da luz, enquanto o problema 2 envolve conhecimentos relativos às reações químicas.

Além disso, considerando as especificidades de cada problema, destacamos que eles demandavam do sujeito habilidades distintas quanto a análise de evidências, proposição de justificativas e elaboração de conclusões. No primeiro caso, o sujeito deveria analisar a situação-problema, elencar os dados que poderiam ser usados como evidências para sustentar sua conclusão, elaborar previsões do que ocorreria na situação investigada e propor uma justificativa, a partir de seus conhecimentos prévios, que ajudasse a conectar a evidência selecionada à conclusão estabelecida. Por outro lado, no segundo caso, as evidências e a conclusão foram enfatizadas pelas próprias questões realizadas pela pesquisadora, portanto, o sujeito deveria apenas mobilizar as justificativas que o permitissem conectar as evidências à conclusão observada ou relacionar 
o conjunto de evidência e propor uma justificativa que fosse coerente com a conclusão. Em outras palavras, na situação 2, o sujeito deveria elaborar explicações a partir de seus conhecimentos prévios e dos dados observados.

As entrevistas ocorreram de uma forma dinâmica, tentando seguir o fluxo de uma conversação, e todas as entrevistas foram registradas em vídeo, tendo sido, posteriormente, transcritas.

\section{Análise de dados}

A opção pelos EAW se deveu ao seu uso satisfatório anteriormente na análise de argumentos dos estudantes de Ensino Médio, por possibilitar a consideração do tipo de raciocínio empregado pelos alunos para justificar suas ideias (IBRAIM et al., 2013). Isso se mostrou relevante para perceber a influência do contexto (tipo de problema) e para valorizar a amplitude de argumentos expressos pelos estudantes.

O fato de as autoras terem tido experiência em trabalhar com os 60 EAW em outras situações de análise também contribuiu para o procedimento de análise realizado neste trabalho. Como uma evidência desta contribuição, podemos citar o fato de termos iniciado o procedimento de análise com base nas categorias gerais apresentadas em Ibraim et al. (2013) (quadro 1). Como mencionado anteriormente, as autoras propuseram alocar os EAW em categorias mais amplas, de forma que os EAW que apresentavam uma natureza similar foram elencados em uma mesma categoria. Neste trabalho, as pesquisadoras destacaram indícios de relação entre tais categorias e os contextos de produção dos EAW.

Diante dessa consideração, iniciamos a nossa análise a partir de um entendimento geral sobre os EAW. Isso nos permitiu, por exemplo, supor que nas situações-problema investigadas não haveria manifestação de EAW relacionados às categorias de Julgamento de Valor e Regra e Exceção, as quais foram propostas por Ibraim et al. (2013). Isso porque, para as licenciandas expressarem os EAW relacionados à categoria de Julgamento de Valor, as situações-problema deveriam apresentar condições para elas atacarem o caráter de um indivíduo ou presumir que as ações deste não seriam coerentes com o que ele defende. Em relação à categoria Regra e Exceção, avaliamos que alguns EAW pertencentes a essa classe, em específico aqueles que envolvem a classificação verbal de um termo, não seriam expressos pelas licenciandas, visto que as questões não solicitavam definição de alguma propriedade ou característica. Assim, nessa primeira análise, baseada nas categorias gerais de Ibraim et al. (2013), foi possível eliminar sete $\mathrm{EAW}^{4}$ referentes a Julgamento de Valor, e dez EAW ${ }^{5}$ relacionados à categoria de Regra e Exceção. Portanto, passamos a utilizar no processo de análise 43 EAW. 
Quadro 1 - Categorias dos EAW propostas por Ibraim et al. (2013)

\begin{tabular}{|c|c|c|c|}
\hline $\begin{array}{c}\text { Esquemas } \\
\text { argumentativos de } \\
\text { Conhecimento } \\
\text { Pessoal }\end{array}$ & $\begin{array}{c}\text { Esquemas } \\
\text { argumentativos de } \\
\text { Julgamento de } \\
\text { Valor }\end{array}$ & $\begin{array}{c}\text { Esquemas } \\
\text { argumentativos de } \\
\text { Regra e Exceção }\end{array}$ & $\begin{array}{c}\text { Esquemas } \\
\text { argumentativos de } \\
\text { Raciocínio }\end{array}$ \\
\hline \multirow[t]{4}{*}{$\begin{array}{l}\text { Posição de } \\
\text { conhecimento; } \\
\text { Opinião de } \\
\text { especialista; } \\
\text { Depoimento de } \\
\text { testemunha; Opinião } \\
\text { popular; Prática } \\
\text { popular;Percepção; } \\
\text { Memória }\end{array}$} & \multirow[t]{4}{*}{$\begin{array}{l}\text { Ethotic }^{7} ; \\
\text { Ad hominem } \\
\text { Genérico; } \\
\text { Inconsistência } \\
\text { pragmática; } \\
\text { Compromisso } \\
\text { inconsistente; } \\
\text { Ad hominem } \\
\text { Circunstancial; } \\
\text { Enviesado; } \\
\text { Ad hominem } \\
\text { Enviesado }\end{array}$} & \multirow[t]{4}{*}{$\begin{array}{l}\text { Gradualismo; Ladeira } \\
\text { escorregadia; Ladeira } \\
\text { escorregadia precedente; } \\
\text { Ladeira escorregadia sorites }{ }^{9} ; \\
\text { Ladeira escorregadia verbal; } \\
\text { Ladeira escorregadia completa; } \\
\text { Constituição de regras } \\
\text { afirmativas; Regras; Caso } \\
\text { excepcional; Precedente; Pedido } \\
\text { de desculpa; Classificação } \\
\text { verbal; Definição para a } \\
\text { classificação verbal; Imprecisão } \\
\text { de uma classificação verbal; } \\
\text { Arbitrariedade de uma } \\
\text { classificação verbal }\end{array}$} & $\begin{array}{l}\text { Raciocínio comparativo: } \\
\text { Exemplo; Analogia; } \\
\text { Raciocínio prático de } \\
\text { analogia; Composição; } \\
\text { Divisão; Interação de ação } \\
\text { pessoal; Valor; Sacrifício; } \\
\text { Grupo e seus membros; } \\
\text { Ignorância; Epistêmico de } \\
\text { ignorância }\end{array}$ \\
\hline & & & $\begin{array}{l}\text { Raciocínio hipotético: Causa } \\
\text { e efeito; Correlação com a } \\
\text { causa; Sinal; Abdutivo; } \\
\text { Evidência para uma hipótese }\end{array}$ \\
\hline & & & $\begin{array}{l}\text { Raciocínio de precedente: } \\
\text { Raciocínio prático; } \\
\text { Raciocínio prático de duas } \\
\text { pessoas; Desperdício, Custos } \\
\text { irrecuperáveis; } \\
\text { Consequência; Alternativa; } \\
\text { Alternativa pragmática; } \\
\text { Aviso; Apelo para o medo; } \\
\text { Apelo para o perigo; } \\
\text { Necessidade de ajuda; } \\
\text { Perigo; Compromisso }\end{array}$ \\
\hline & & & $\begin{array}{l}\text { Raciocínio de alternativa: } \\
\text { Oposição: Retórico de } \\
\text { oposição; Alternativas }\end{array}$ \\
\hline
\end{tabular}

Fonte: Ibraim et al., 2013, p. 171.

Após a primeira etapa de análise, buscamos utilizar os 43 EAW para analisar as respostas apresentadas pelas professoras em formação nas situaçõesproblema. Nessa segunda etapa, cada pesquisadora classificou de forma independente as respostas utilizando os EAW. No processo de triangulação dos dados, notamos que o índice de compatibilidade das classificações entre as autoras não foi satisfatório. Por isso, buscamos compreender os motivos que poderiam ter contribuído para tais divergências no processo de análise, e percebemos que isso estava associado ao fato de as pesquisadoras terem classificado uma mesma resposta utilizando diferentes esquemas, entretanto, estes eram próximos e as diferenças representavam nuanças na sua interpretação.-

Diante dessa situação, sentimos necessidade de voltar ao livro Argumentation schemes de Walton et al, (2008) com objetivo de rever as definições dos autores. No entanto, percebemos que muitas de nossas dúvidas não foram solucionadas apenas através da leitura desse livro, visto que neste não há detalhes de todos os 60 EAW. Desse modo, tivemos que buscar outros livros e artigos que fornecessem mais detalhes de cada esquema, esse processo foi bastante moroso. Para alguns casos, o autor é o próprio Douglas Walton (por exemplo MACAGNO; WALTON; TINDALE, 2014; MACAGNO; WALTON, 2015; WALTON, 1992, 1996, 
1999b, 2001, 2002, 2006a, 2006b, 2008, 2009a, 2009b, 2014a, 2014b; WALTON; MACAGNO, 2009; WALTON; MACAGNO, 2015), outros são de pesquisadores que fizeram o uso dessa ferramenta no campo da educação, como: JiménezAleixandre e Pereiro Muñoz (2002), Duschl (2008), Macagno e Konstantinidou (2012), Ozdem, Ertepinar, Cakiroglu e Erduran (2013), Kim et al. (2014) e Macagno, Mayweg-Paus e Kuhn (2015). A partir desse estudo detalhado sobre os EAW, buscamos reelaborar as definições gerais dos EAW a partir das nossas interpretações sobre estes com base nas leituras mencionadas.

De posse das novas definições dos EAW, demos início ao processo de análise das situações de entrevistas. Para realização da análise, seguimos alguns passos, caracterizados a seguir.

1. Classificação dos argumentos apresentados na situação-problema $1 \mathrm{com}$ base nos 43 EAW, realizada por cada pesquisadora de forma independente, seguida de processo de triangulação dos resultados. A triangulação foi feita com o intuito de obter consenso e atribuir confiabilidade à análise, que foi em torno de 85\% (COHEN; MANION; MORRISON, 2011). Optamos por iniciar a análise pela situação-problema 1, uma vez que esta apresentava um número menor de questões e, consequentemente, de respostas. A análise da situação-problema 1 significou uma oportunidade de as pesquisadoras mobilizarem seu entendimento sobre os EAW e discutirem sobre eles.

2. Reconstrução dos argumentos expressos pelas professoras em formação na situação-problema 1 com o intuito de facilitar a visualização do esquema utilizado na classificação, mantendo o mesmo sentido que elas disseram. Utilizamos códigos para os professores em formação (PF1 a PF5), para resguardar suas identidades, e SP para distinguir as situaçõesproblema, sendo SP1 para o problema boneco de neve e SP2 para queima da vela. A seguir, há uma reformulação do argumento elaborado por PF5 construído na entrevista SP1:

Entrevistadora: "Vou te apresentar esses dois bonecos de neve. Eles estão no mesmo ambiente, na mesma temperatura, tem a mesma massa e o mesmo formato. A única coisa que eles têm de diferente é que o Fred está com casaco e o Bob não. Aí, eu queria que você me dissesse qual dos dois você acha que derrete primeiro e o porquê disso."

PF5: "O vestido porque ele estará absorvendo, no caso, os raios, o calor, então, ele vai se manter por mais tempo. Então, acredito que é o vestido." Entrevistadora: "Você acha que ele estará absorvendo por causa do casaco?" PF5: "Porque na verdade ele vai absorver. E, além disso, talvez, no primeiro momento, esse derreta (o boneco sem casaco, Bob). A temperatura desse daqui (boneco com casaco, Fred) vai ser maior do que deste (o boneco sem casaco, Bob)."

Entrevistadora: "Ah! Por causa do casaco?"

L5: "Isso!"

Argumento reformulado: Se o casaco absorve os raios solares, a temperatura se eleva, e o Fred derrete primeiro. [EAW causa para efeito].

3. Produção de tabelas analíticas individuais contendo a classificação de cada argumento para SP1. 
4. Realização da análise das respostas proferidas pelas licenciandas na situação problema 2. Para essa análise, seguimos os mesmos passos descritos acima ( 1 a 3 ). Nesse caso, vale destacar que, ao realizar a primeira análise, tivemos a oportunidade de discutir e alinhar os nossos entendimentos sobre os esquemas, e isso implicou o fato de a análise da situação-problema 2 ter tido um índice de confiabilidade maior, em torno de $92 \%$. Assim como na situação anterior, os casos divergentes foram discutidos buscando estabelecer consenso.

5. Produção de tabela analítica geral, a partir das tabelas analíticas individuais, com o objetivo de identificar os EAW predominantes no problema 1 e 2 para favorecer as discussões das possíveis influências do contexto na manifestação dos argumentos expressos pelas professoras em formação inicial.

Após análise das duas situações-problema, discussão sobre os casos divergentes buscando estabelecer consenso e criação de tabelas analíticas, discutimos os resultados tabulados à luz das questões de pesquisa.

\section{RESULTADOS E DISCUSSÃO}

A partir do processo de análise utilizando os 43 EAW, avaliamos que os argumentos manifestados pelas professoras em formação inicial puderam ser classificados de acordo com sete tipos de EAW. No Quadro 2, apresentamos a descrição detalhada dos EAW expressos pelas professoras em formação ao longo das situações-problema. $\mathrm{Na}$ Tabela 1, apresentamos o número de argumentos classificados em função dos EAW para cada um dos problemas.

Quadro 2 - EAW encontrados nos argumentos produzidos pelas professoras em formação

\begin{tabular}{ll}
\multicolumn{1}{c}{$E A W$} & \multicolumn{1}{c}{ Descrição } \\
\hline $\begin{array}{l}\text { Causa para } \\
\text { efeito }\end{array}$ & $\begin{array}{l}\text { Referência a premissas que estão casualmente ligadas } \\
\text { a um efeito não controverso, isto é, a um resultado } \\
\text { observado que não precisa ser testado. Aqui, a ideia } \\
\text { condicional não é absoluta. Portante, se "A" ocorre, } \\
\text { "B” não necessariamente precisa ocorrer. É apenas } \\
\text { uma generalização que pode ser falseada. }\end{array}$ \\
$\begin{array}{l}\text { Evidência } \\
\text { para } \\
\text { hipótese }\end{array}$ & $\begin{array}{l}\text { Referência a premissas seguidas por uma } \\
\text { conclusão. }\end{array}$ \\
& $\begin{array}{l}\text { Inclui uma hipótese, isto é, uma conjectura ou } \\
\text { previsão generalizável capaz de ser testada. }\end{array}$ \\
Sinal & $\begin{array}{l}\text { Referência à conclusão que é possível de ser } \\
\text { inferida a partir de um ou mais dados. A conclusão }\end{array}$ \\
& $\begin{array}{l}\text { é hipotética, mas é plausível a partir do conjunto } \\
\text { de dados disponíveis. Ele também é nomeado }\end{array}$ \\
& $\begin{array}{l}\text { como argumento de efeito para causa, uma vez } \\
\text { que o objetivo é buscar as causas das evidências } \\
\text { disponíveis (efeito). }\end{array}$
\end{tabular}

"Como não há mais oxigênio para realizar a combustão, a vela apaga." (PF3) "Abaixo da temperatura de congelamento, o Fred vai derreter primeiro, pois o casaco, sendo preto, facilita a absorção de energia." (PF5)

\footnotetext{
"Se o material do casaco do Fred fosse isolante, o Bob derreteria primeiro, porque estaria impedindo a troca de calor." (PF5) (PF3)
"Como tem bolhas, pode-se inferir que entrou oxigênio por baixo." (PF4)

"O Bob, por estar protegido, derreterá primeiro."
} 
Gradualismo Referência a uma proposição "C" que é considerada verdadeira a partir de uma proposição "A" (considerada aceitável) se há uma sequência de proposições " $\mathrm{B}_{1}, \mathrm{~B}_{2}, \ldots \mathrm{B}_{\mathrm{n}-1}, \mathrm{~B}_{\mathrm{n}}, \mathrm{C}$ ", de forma que uma ser verdadeira implica em a seguinte também ser. Uma sequência de similaridades pode levar à aceitação de uma conclusão absurda.

Alternativa

Referência a duas opções em que a escolha de uma delas se dá a partir de exclusão da outra, com base na análise de suas plausibilidades.

Alternativa

Referência a ações que devem ser tomadas para a concretização de um objetivo.

Correlação para causa
"Eu concordo com o que Fred disse, pois como ele está com um casaco que é preto, o mesmo va absorver mais energia e mais anergia vai incidir nele. Portanto, pode-se presumir que o Fred irá derreter mais rápido.” (FP2)

"Eu acho que o Bob derrete primeiro, porque o Fred está com a blusa de frio que é um isolante térmico." (FP3)

"Eu gosto mais da minha explicação, que a falta de oxigênio seja o motivo da vela ter apagado, pois eu não acho que o vapor é suficiente para apagar a chama da vela.”(FP3)

"Eu mandaria o Bob colocar o casaco e ir para o sol, pois assim ele veria que derreteria mais rápido do que se ele não e estivesse com casaco.” (PF2)

"O consumo de oxigênio permitiu que a água subisse por capilaridade na vela, fazendo-a apagar." (PF1)

Fonte: Elaboração pelos autores deste artigo.

Tabela 1 - Número de argumentos em função da classificação quanto aos EAW manifestados por cada professora em cada um dos problemas

\begin{tabular}{|c|c|c|c|c|c|c|c|c|c|c|c|c|}
\hline \multirow[b]{2}{*}{$E A W$} & \multicolumn{5}{|c|}{$P 1$} & \multicolumn{7}{|c|}{$P 2$} \\
\hline & L1 & L2 & L3 & L4 & L5 & $\begin{array}{l}\text { Total } \\
\text { EAW }\end{array}$ & L1 & L2 & L3 & L4 & L5 & $\begin{array}{l}\text { Total } \\
\text { EAW }\end{array}$ \\
\hline $\begin{array}{c}\text { Causa para } \\
\text { efeito }\end{array}$ & 01 & 01 & 02 & 02 & 02 & 08 & 04 & 02 & 01 & 03 & 02 & 12 \\
\hline $\begin{array}{c}\text { Evidência } \\
\text { para } \\
\text { hipótese }\end{array}$ & 02 & - & 02 & 01 & 02 & 07 & - & - & - & - & - & - \\
\hline Sinal & 01 & - & 01 & 01 & - & 03 & 01 & 02 & 01 & 01 & - & 05 \\
\hline Gradualismo & 01 & 01 & - & - & - & 02 & - & - & - & - & - & - \\
\hline Alternativa & - & - & 01 & 01 & 01 & 03 & 01 & - & 01 & - & - & 02 \\
\hline $\begin{array}{c}\text { Raciocínio } \\
\text { prático }\end{array}$ & - & 01 & - & - & - & 01 & - & - & - & - & - & - \\
\hline $\begin{array}{l}\text { Correlação } \\
\text { para causa }\end{array}$ & - & - & - & - & - & - & 01 & 01 & - & 02 & 02 & 06 \\
\hline TOTAL & & & & & & 24 & & & & & & 25 \\
\hline
\end{tabular}


Os argumentos foram classificados em sete EAW, sendo predominantes aqueles relacionados ao raciocínio científico (causa para efeito, sinal, evidência para hipótese e correlação para causa), assim como constatado em outras pesquisas cujos problemas envolviam conhecimentos científicos (OZDEM et al., 2013; DUSCHL, 2008; KIM et al., 2013). Notamos que o esquema de gradualismo não foi classificado dentro do raciocínio científico por esses autores citados. No entanto, julgamos que ele possa ser inserido nessa categoria, uma vez que nesse tipo de esquema há várias relações de causa para efeito que podem ser estabelecidas. Além disso, diferente do que foi observado por Konstandinidou e Macagno (2013), que classificaram os argumentos dos estudantes universitários em dois tipos (analogia e causa para efeito), não observamos o esquema analogia na análise de dados referente ao problema 1. No caso dos pesquisadores citados, os estudantes recorreram a comparações entre o domínio análogo (função de um casaco para "aquecer" uma pessoa) e o domínio alvo (função do casaco para o boneco de neve) para embasar seus argumentos. Em nossos dados, não verificamos o raciocínio analógico como fundamento para o argumento do tipo analogia, isto é, não percebemos um mapeamento de relações entre os domínios comparados (MOZZER; JUSTI, 2015), apesar de termos verificado menções a situações do cotidiano (como um ser humano colocar um casaco e ter sensação de quente). Em trabalho anterior de Ibraim el al. (2013), constatamos apenas um único caso de EAW analogia para o problema do boneco de neve.

O número de argumentos classificados nos dois problemas para as cinco professoras foi similar (24 SP1 e 25 SP2). Constatamos que há relação entre a natureza dos fenômenos investigados e os esquemas argumentativos mobilizados pelas professoras em formação. Em outras palavras, observamos uma influência desses aspectos nos argumentos formulados pelas professoras em formação. Em função das habilidades distintas mobilizadas na resolução dos problemas, observamos o aparecimento do esquema evidência para hipótese apenas em SP1 e correlação com causa apenas em SP2. Isso pode indicar que certos tipos de esquema podem ser mais usuais em determinadas situações-problema. Por exemplo, o problema dos bonecos de neve favorece a elaboração do esquema evidência para hipótese, pois o sujeito pode supor condições (pensar se os bonecos estavam em um ambiente cuja temperatura era acima ou abaixo do congelamento da água) para propor seu argumento, como foi feito por PF4: "Se estiver quente, o Fred por estar com casaco vai absorver calor e, assim, derrete primeiro. E, se estiver frio, o Fred por ter uma temperatura um pouco mais elevada do que a do boneco sem casaco, derrete primeiro" (Argumento de PF4, em SP1).

Por outro lado, como o problema da queima da vela tem como objetivo a produção de uma explicação, ele exige que os sujeitos construam argumentos que mostrem correlação entre dois eventos, sendo que um deles é a causa do outro. Isso pode ser observado no argumento de PF1: "O consumo de oxigênio permitiu que a água subisse por capilaridade na vela, fazendo-a a apagar".

Outro aspecto que observamos foi o não aparecimento de alguns esquemas argumentativos. Por exemplo, não foram observados EAW que envolvem o estabelecimento de compromisso (por exemplo, os esquemas argumentativos de compromisso, de compromisso inconsistente e de inconsistência pragmática). Avaliamos que a não manifestação desse tipo de EAW pelas licenciandas pode estar relacionada tanto à natureza dos problemas ser científica quanto às próprias questões da 
entrevista. Isso porque as questões apresentadas visavam sondar as explicações para os fenômenos científicos. Portanto, os sujeitos deveriam mobilizar seus conhecimentos com o objetivo de justificar os fenômenos observados.

O EAW de raciocínio prático foi mobilizado apenas uma vez pelas professoras em formação inicial. Esse tipo de esquema é bastante utilizado em nosso dia a dia quando nos referimos a ações que devemos executar para atingir determinado objetivo (WALTON et al., 2008). Portanto, provavelmente, as futuras professoras tiveram a oportunidade de mobilizar tal esquema em situações cotidianas. Sendo assim, consideramos que as questões presentes nos protocolos de entrevista pouco favoreciam a mobilização desse esquema.

Em geral, julgamos que a não manifestação de alguns EAW pode estar relacionada ao tipo de metodologia de coleta de dados. A entrevista utilizada neste trabalho apresentava um número de questões reduzido (em torno de sete questões para SP1 e 17 questões para SP2), o que pode ter contribuído para o fato de as professoras em formação inicial apresentarem uma pequena quantidade de variedade de esquemas.

Além disso, o tipo de ensino vivenciado pelos sujeitos da pesquisa pode ter influência na manifestação de alguns esquemas. Por exemplo, observamos a baixa incidência do esquema argumentativo de alternativa em ambos os contextos científicos, sendo que, no problema do boneco de neve, 12,5\% dos argumentos manifestados pelas professoras apresentaram esse padrão de raciocínio, enquanto, no outro, apenas 8,0\%. Acreditamos que, nesse caso, a baixa expressão desse tipo de esquema pode não estar relacionada ao contexto de entrevista, uma vez que durante ela as professoras foram solicitadas a avaliar as teorias existentes e selecionar aquela que fosse mais plausível, assim como pensar em uma teoria alternativa à que elas haviam indicado e justificar sua possível plausibilidade.

Diante disso, consideramos que a baixa incidência de EAW do tipo alternativa pode estar relacionada ao processo de ensino vivenciado pelas professoras em formação ao longo das disciplinas de conteúdo químico. Isso porque, em geral, essas disciplinas são pautadas em um modelo tradicional de ensino no qual o professor trabalha com o conhecimento de forma reificada. Quando o conhecimento científico é reificado, ele deixa de ser considerado um artefato cultural que é construído socialmente e passa a ser considerado um fato inquestionável (LATOUR, 2000), isto é, não favorece a discussão do porquê de um conhecimento ser considerado adequado ou inadequado do ponto de vista científico. Em outras palavras, esse tipo de ensino não dá oportunidade aos licenciandos de participar de situações argumentativas envolvendo os conteúdos discutidos, isto é, de eles refletirem sobre as evidências e as justificativas possíveis para tais conteúdos. A colocação feita por Walton et al. (2008) sobre o fato de esse tipo de esquema ser proferido em situações de debates e controvérsias sustenta a nossa hipótese de que, por as licenciandas vivenciarem um ensino de química que não favorecia suas participações no processo de análise do porquê de uma resposta correta ser correta ou vice-versa etc., isso influenciou a manifestação do esquema alternativa pelas futuras professoras ao longo das entrevistas.

Vale destacar que, embora tenhamos buscado compreender os motivos que possam ter contribuído para o aparecimento de determinados esquemas em nosso estudo, reconhecemos que tal compreensão reside no campo das hipóteses. 
Em outras palavras, sem um estudo que utilize instrumentos de coleta de dados que permitam acessar tanto os esquemas mobilizados quanto sondar o porquê de determinados esquemas não serem proferidos, não é possível determinar quais fatores influenciaram ou não o aparecimento dos esquemas. Porém, salientamos que, nesse sentido, nosso estudo chama a atenção para a necessidade de mais pesquisas que avaliem as relações entre o contexto de pesquisa vivenciado pela amostra, a metodologia e ocorrência de determinados esquemas.

\section{CONCLUSÕES E IMPLICAC̣ÕES}

Tendo em vista a primeira questão de pesquisa, a análise realizada apontou que os professores em formação inicial produziram 24 argumentos na primeira entrevista e 25 argumentos na segunda entrevista, totalizando 49 argumentos. Considerando todos os argumentos produzidos, foi possível observar a ocorrência de sete tipos de EAW, sendo eles: causa para efeito; evidência para hipótese; sinal; gradualismo; alternativa; raciocínio prático; e correlação com causa. Entretanto, observamos a ocorrência do esquema evidência para hipótese apenas em SP1 e correlação com causa apenas em SP2. Diante disso, destacamos que há relação entre os esquemas observados e as situações-problema investigadas. Em outras palavras, o tipo de situação-problema pode favorecer ou não a ocorrência de determinados esquemas.

Além disso, essa observação sugere algo interessante para situações de ensino: pensar em trabalhar com diferentes situações-problema e, assim, fomentar a mobilização de diferentes tipos de esquema no desenvolvimento do raciocínio científico dos estudantes. Por exemplo, como comentado anteriormente, o problema do boneco de neve favoreceu a criação de hipóteses e, a partir destas, a mobilização de evidências que poderiam reforçar ou refutar um ponto de vista.

Sobre a forma de classificação dos argumentos utilizando os 60 EAW, defendemos que as respostas podem ser classificadas por esse referencial a partir, primeiramente, da delimitação delas, e seguidas da utilização das categorias propostas por Ibraim et al. (2013). Não tivemos dificuldades em delimitar as respostas, possivelmente, por tratar-se de situações de entrevistas e por as respostas das professoras serem relativamente curtas para cada questão. Entretanto, em alguns momentos, para delimitar a resposta, foi preciso observar um trecho maior da entrevista para identificar a lógica do raciocínio apresentado pelas professoras em formação. Possivelmente, em situações de sala de aula, nas quais ocorrem diálogos mais dinâmicos (em comparação a respostas escritas ou entrevistas individuais), a delimitação dos enunciados se torna um trabalho mais complexo. Para facilitar tal tarefa, sugerimos avaliar o contexto em que os enunciados estão sendo emitidos. Nesse sentido, os EAW são úteis, uma vez que permitem avaliar as inferências realizadas pelos sujeitos em seus raciocínios envolvidos na expressão de justificativas e conclusões. Em relação às categorias, elas foram úteis para nos auxiliar no processo da classificação dos argumentos em um primeiro momento, porque permitiram que eliminássemos alguns EAW a partir de uma análise mais ampla.

Outros pontos importantes na utilização dos EAW para classificação de argumentos são o conhecimento das categorias pelo(s) pesquisador(es) e a 
triangulação da análise com o objetivo de chegar a um consenso. Tal aspecto é fundamental para qualquer tipo de análise. Contudo, ele é salientado nesse trabalho pela necessidade de conhecer o extenso número de EAW.

Sobre as contribuições de utilizar os 60 EAW para avaliar os argumentos produzidos pelas professoras em formação, destacamos que o uso dessa ferramenta se mostrou favorável para a análise de argumentos em contextos científicos, pois ela nos permitiu classificar uma variedade de argumentos apresentados pelas professoras em formação inicial ao longo das entrevistas.

Em contrapartida, na literatura, temos encontrado trabalhos que têm tanto se baseado em um número restrito de EAW para realizar a análise dos argumentos quanto na criação de categorias mais amplas a partir da junção de alguns EAW. Isso se justifica pela dificuldade de trabalhar com vários esquemas ou pela natureza dos problemas envolvida em contextos do ensino de ciências. Reconhecemos que essas estratégias possam ser proveitosas nos casos em que a delimitação de um esquema é muito complexa ou próxima à de outro esquema. Pois isso poderia resultar na diminuição dos riscos de os pesquisadores elaborarem inferências inadequadas e de a validade da análise ser comprometida. Além disso, tais estratégias se mostram válidas, principalmente, quando o pesquisador não está acostumado com o uso deste referencial teórico.

Diante dessas considerações, concluímos que o uso dos 60 EAW tem potenciais contribuições para a análise de argumentos, e o fato de o pesquisador contar com uma gama de esquemas permite que ele faça uma análise menos subjetiva. Isso porque a interpretação do pesquisador em relação ao argumento do sujeito não é restringida por uma seleção prévia de esquemas e, consequentemente, dos tipos de raciocínios envolvidos. Entretanto, assim como ressaltado pela literatura, reconhecemos que o uso dos 60 EAW para análise pode ser desafiador para o pesquisador, devido ao fato de alguns esquemas apresentarem definições complexas e de haver esquemas que são desdobramentos de outros esquemas argumentativos. Acreditamos que esses fatores, associados à necessidade do pesquisador de ter um amplo conhecimento sobre cada um dos 60 esquemas, podem significar uma limitação no uso da ferramenta.

Portanto, tendo em vista que: (i) problemas tratados influenciam a mobilização dos esquemas; (ii) a elaboração de definições gerais a partir das intepretações para os esquemas pode possibilitar uma melhor compreensão dos EAW e contribuir para uma visão não estereotipada ou restrita em relação aos tipos de esquema apresentados em contextos específicos; (iii) o trabalho com um número limitado de EAW para análise de argumentos em problemas científicos ser mais prático, porém comprometedor; e (iv) a dificuldade de definir e utilizar os 60 EAW para a análise de argumentos, acreditamos que haja necessidade de realizar mais pesquisas que investiguem as contribuições de se utilizar categorias mais amplas ou um número limitado de esquemas na análise de argumentos em relação ao uso dos 60 EAW.

Além disso, consideramos que esse trabalho aponta para uma nova direção: Será que a melhor estratégia seria a construção de uma nova ferramenta a partir dos 60 EAW? Essa ferramenta poderia ser construída baseada no entendimento dos 60 EAW, porém, seriam criadas novas categorias que seriam constituídas a partir das 
ideias gerais envolvidas nos esquemas argumentativos, isto é, pela essência de uma classe deles e não pelas suas definições. É importante destacar que essa proposta se difere do uso de categorias mais amplas, como usado por Kim e colaboradores (2014). Por exemplo, ao trabalhar com categorias amplas, o pesquisador ainda precisa classificar os argumentos a partir dos esquemas. Nesse sentido, as categorias mais amplas apenas guiam o pesquisador no processo de classificação do argumento, uma vez que ele parte de um número menor que apresenta características similares, em vez de ele classificar a partir da análise de todos os 60 EAW. Por outro lado, a nova ferramenta poderia isentar o pesquisador da tarefa de conhecer todos os esquemas e de ter habilidade em classificar argumentos a partir deles.

Para finalizar, acreditamos que a situação de entrevista seja uma forma metodológica que pode atender a vários objetivos de pesquisas. No entanto, a julgamos como limitada quando se quer investigar a qualidade argumentativa dos professores, isto é, se os argumentos são fracos ou fortes. Isso porque essa situação pouco propicia ao sujeito a oportunidade de refletir ou perceber as lacunas de seus argumentos. Tal aspecto poderia ocorrer mais facilmente em situações de debate, uma vez que os indivíduos poderiam apresentar opiniões divergentes das dos seus colegas e trazer para as discussões elementos que subsidiassem seus argumentos ou os refutassem (momentaneamente) para convencer o outro. Situações como essas podem favorecer a elaboração pelos professores de questões críticas que avaliam o argumento do outro, bem como desenvolver outros padrões de raciocínios. Portanto, julgamos ser interessante trabalhar com o referencial analítico de Walton et al. (2008) em situações de debate durante a formação inicial de professores com o objetivo de favorecer o desenvolvimento de uma melhor qualidade argumentativa.

\section{NOTAS}

${ }^{1}$ Toulmin's argumentation pattern. Optamos por apresentar a sigla em inglês em função de sua ampla utilização na literatura mundial.

${ }^{2}$ Como exemplo de silogismo temos: Todo homem é mortal (premissa maior). Sócrates é homem (premissa menor). Logo, Sócrates é mortal (conclusão).

${ }^{3}$ Como exemplo de uma construção de silogismo inadequada temos: Materiais que conduzem corrente elétrica são metais (premissa maior). Grafite conduz corrente elétrica (premissa menor). Logo, grafite é metal (conclusão).

${ }^{4}$ Os EAW que abrangem a categoria de Julgamento de Valor são: Ad hominem Genérico; Inconsistência pragmática; Compromisso inconsistente; Ad hominem Circunstancial; Enviesado; Ad hominem Enviesado.

${ }^{5}$ Alguns EAW que abrangem a categoria Regra e Excesso, os que envolvem a classificação vebal de um termo: Ladeira escorregadia precedente; Ladeira escorregadia sorites; Ladeira escorregadia verbal; Constituição de regras afirmativas; Caso excepcional; Pedido de desculpa; Classificação verbal; Definição para a classificação verbal; Imprecisão de uma classificação verbal; Arbitrariedade de uma classificação verbal. 


\section{REFERÊNCIAS}

ABI-EL-MONA, Issam; ABD-EL-KHALICK, Fouad. Perceptions of the nature and 'Goodeness' of argument among college students, science teachers, and scientists. International journal of science education, London, v. 33, n. 4, p. 573-605, 2011.

ANTHONY, Robert; KIM, Mijung. Challenges and Remedies for Identifying and Classifying Argumentation Schemes. Argumentation, Dordretch, v. 29, n. 1, p. 81-113, 2015.

BERLAND, Leema K.; REISER, Brian J. Making sense of argumentation and explanation. Science education, Hoboken, v. 93, n. 1, p. 26-55, 2009.

CARMO, Alez C.; CARVALHO, Ana Maria P. Múltiplas linguagens e a matemática no processo de argumentação em uma aula de física: Análise dos dados de um laboratório aberto. Investigações em ensino de ciências, Porto Alegre, v. 17, p. 209-226, 2012.

COHEN, Louis; MANION, Lawrence; MORRISON, Keith. Research methods in education. $7^{\text {th }}$ ed. London: Routledge, 2011.

CORREA, Heberton. Análise das capacidades argumentativas de professores de química recémformados na Universidade Federal de Minas Gerais. 124. Mestrado - Faculdade de Educação, Universidade Federal de Minas Gerais, Belo Horizonte, 2011.

DRIVER, Rosalinda; NEWTON, Paul; OSBORNE, Jonathan. Establishing the norms of scientific argumentation in classrooms. Science education, Hoboken, v. 84, n. 3, p. 287-312, 2000.

DUSCHL, Richard A. Quality argumentation and epistemic criteria. In: ERDURAN, Sibel; JIMÉNEZ-ALEIXANDRE, Maria Pilar (Ed.). Argumentation in science education: Perpectives from classroom-based research. Dordretch: Springer, 2008. p. 159-170.

DUSCHL, Richard A.; ELLENBOGEN, Kirsten. Understanding dialogic argumentation among middle school sience students. 1999. In: THE ANNUAL CONFERENCE OF AMERICAN EDUCATIONAL RESEARCH ASSOCIATION, Montreal. Comunicação oral.

DUSCHL, Richard A.; OSBORNE, Jonathan. Supporting and promoting argumentation discourse in science education. Studies in science education, London, v. 38, p. 39-72, 2002.

ERDURAN, Simon.; JIMÉNEZ-ALEIXANDRE, P. Argumentation in science education: Perspectives form classroom-based research. Dordrecht: Springer, 2008.

GARCIA-MILA, Merce; ANDERSEN, Christoper. Cognitive foundations of learning argumentation. In: ERDURAN, Sibel; JIMÉNEZ-ALEIXANDRE, Maria Pilar (Ed.). Argumentation in science education: Perspectives from classroom-based research. Dordrecth: Springer, 2008. p. 29-46.

IBRAIM, Stefannie; MENDONÇA, Paula; JUSTI, Rosária. Contribuições dos Esquemas Argumentativos de Walton para análise de argumentos no contexto do ensino de ciências. Revista Brasileira de Pesquisa em Educação em Ciências, Belo Horizonte, v. 13, n. 1, p. 159-185, 2013.

JIMÉNEZ-ALEIXANDRE, M. P. 10 ideas clave: competencias en argumentación y uso de pruebas. Barcelona: Graó, 2010.

JIMÉNEZ-ALEIXANDRE, Maria. P.; BUGALLO, Anxela Rodríguez. "Doing the lesson" or "Doing science": Argument in high school genetics. Science education, Hoboken, v. 84, n .6, p. 757-792, 2000. KIM, Mijung; ANTHONY, Robert; BLADES, David. Decision making through dialogue: a case study of analysing preservice science teachers' argumentation on socioscientific issues. Research in Science Education, Dordrecht, v. 44, n. 6, p. 903-926, 2014.

KOLSTO, Stein D.; RATCLIFFE, Mary. Social aspects of argumentation. In: ERDURAN, Sibel; JIMÉNEZ-ALEIXANDRE, Maria Pilar (Ed.). Argumentation in science education: Perpectives from classroom-based research. Dordrecht: Springer, 2008. p. 117-136.

KONSTANTINIDOU, Aikaterini; MACAGNO, Fabrizio. Understanding students' reasoning: 
Argumentation schemes as an interpretation method in science education. Science \& Education, Dordrecht, v. 22, n. 5, p. 1069-1087, 2013.

LATOUR, Bruno. Ciência em ação: Como seguir cientistas e engenheiros sociedade afora. São Paulo: Unesp, 2000.

MACAGNO, Fabrício; WALTON, Douglas; TINDALE, Chistopher. Analogical reasoning and semantic rules of inference. Revue internationale de philosophie, Bruxelas, v. 270, n. 4, p. 419-432, 2014.

MACAGNO, Fabrício; WALTON, Douglas. Classifying the patterns of natural arguments. Philosophy and rhetoric, Filadélfia, v. 48, n. 1, p. 26-53, 2015.

MENDONÇA, Paula; JUSTI, Rosária. The relationships between modelling and argumentation from the perspective of the model of modelling diagram. International journal of science education, London, v. 35, p. 2407-2434, 2013 a.

MENDONÇA, Paula; JUSTI, Rosária. Ensino-aprendizagem de ciências e argumentação: Discussões e questões atuais. Revista Brasileira de Pesquisa em Educação em Ciências, Belo Horizonte, 2013b.

MENDONÇA, Paula; JUSTI, Rosária. An instrument for analysing arguments produced in modelingbased chemistry lessons. Journal of Research in Science Teaching, Hoboken, v. 51, p. 192-218, 2014. MOZZER, Nilmara; JUSTI, Rosária. Nem tudo que reluz é ouro: Uma discussão sobre analogias e outras similariedades e recursos utilizados no ensino de Ciências. Revista Brasileira de Pesquisa em Educação em Ciências, Belo Horizonte, v. 15, n. 1, p. 123-147, 2015.

NIELSEN, Jan. A. Dialetical features of students' argumentation: A critical review of argumentation studies in science education. Research in Science Education, Dordrecht, v. 43, n. 1, p. 371-393, 2013. OSBORNE, Jonathan; ERDURAN, Sibel; SIMON, Shirley. Enhancing the quality of argumentation in school science. Journal of Research in Science Teaching, Hoboken, v. 41, n. 10, p. 994-1020, 2004. OSBORNE, Jonathan. Towards a more social pedagogy in science education: the role of argumentation. Revista Brasileira de Pesquisa em Educação em Ciências, Belo Horizonte, v. 7, n. 1, p. 1-17, 2007.

OZDEM, Yasemin.; ERTEPINAR, Hamide; CAKIROGLU, Jale; ERDURAN, Sibel. The nature of pre-service science teachers' argumentation in inquiry-oriented laboratory context. International Journal of Science Education, London, v. 35, n. 15, p. 2559-2586, 2013.

RIGOTTI, Eddo.; MORASSO, Sara Greco. Argumentation as an object of interest and as a social and cutural resource. In: MIRZA, Nathalie Muller; PERRET-CLERMONT, Anne-Nelly (Ed.). Argumentation and education. Dordrecht: Springer, 2009. p. 9-66.

SÁ, Luciana. P.; QUEIROZ, Salete. L. Promovendo a argumentação no ensino superior de química. Química Nova, São Paulo, v. 30, n. 8, p. 2035-2042, 2007.

SAMPSON, Victor; CLARK, Douglas. Assessment of the ways students generate arguments in science education: Current perspectives and recommendations of future directions. Science Education, Hoboken, v. 92, n. 3, p. 447-472, 2008.

SANDOVAL, Willian. A.; MILLWOOD, Kelli, A. What can argumentation tell us about epistemology? In: ERDURAN, Sibel; JIMÉNEZ-ALEIXANDRE, Maria Pilar (Ed.). Argumentation in Science Education: Perspectives from classroom-based research. Dordrecht: Springer, 2008. p. 71-90.

SASSERON, Lúcia Helena; CARVALHO, Ana Maria P. Construindo argumentação na sala de aula: a presença do ciclo argumentativo, os indicadores de alfabetização científica e o padrão de Toulmin. Ciência \& Educação, Bauru, v. 17, p. 97-114, 2011.

SIMON, Shirley; JOHNSON, Susan. Professional learning portfolios for argumentation in school science. International Journal of Science Education, London v. 30, n. 5, p. 669-688, 2008.

TOULMIN, Stephan. The uses of argument. New York: Cambridge University Press, 1958.

VAN EEMEREN, Frans; GROOTENDORST, Rob; HENKEMANS, Sonoeck; BLAIR, Anthony; JOHNSON, Ralph., KRABBE, Erick; ZAREFSKY, David. Fundamentals of argumentation theory: 
A handbook of historical backgrounds and contemporary developments. Mahwah, New Jersey: Lawrence Erlbaum, 1996.

VON AUSCHNAITER, Claudia; ERDURAN, Sibel; OSBORNE, Jonathan; SIMON, Shirley. Arguing to learn and learning to argue: Case studies of how students' argumentation relates to their scientific knowledge. Journal of Research in Science Teaching, Hoboken v. 45, n. 1, p. 101-131, 2008. WALTON, Douglas. Nonfallacious arguments from ignorance. American Philosophical Quarterly, Champaign, v. 29, n. 4, p. 381-387, 1992.

WALTON, Douglas. Practical reasoning and the structure of fear appeal arguments. Philosophy and rhetoric, Filadélfia, v. 29, n. 4, p. 301-313, 1996 a.

WALTON, Douglas. Argumentation schemes for presumptive reasoning. Mahwah: Erlbaum, 1996b.

WALTON, Douglas. The appeal to ignorance, or argumentum ad ignorantiam. Argumentation, Dordrecht v. 13, n. 4, p. 367-377, 1999a.

WALTON, Douglas. Profiles of dialogue for evaluating arguments from ignorance. Argumentation, Dordrecht, v. 13, n. 1, p. 53-71, 1999b.

WALTON, Douglas. Abductive, presumptive and plausible arguments. Informal Logic, Ontário, v. 21, n. 2, p. 141-169, 2001.

WALTON, Douglas. The sunk costs fallacy or argument from waste. Argumentation, Dordrecht, v. 16, n. 4, p. 473-503, 2002.

WALTON, Douglas. Lógica informal: manual de argumetação crítica. São Paulo: Martins Fontes, 2006a. WALTON, Douglas. Rules for reasoning from knowledge and lack of knowledge. Philosophia, Jerusalem, v. 34, n. 3, p. 355-376, 2006b.

WALTON, Douglas. Arguing from definition to verbal classification: The case of redefining 'planet' to exclude pluto. Informal logic, Ontário, v. 28, n. 2, p. 129-154, 2008.

WALTON, Douglas. Dialectical shifts underlying arguments from consequences. Informal logic, Ontário, v. 29, n. 1, p. 54-83, 2009a.

WALTON, Douglas. Explanations and arguments based on practical reasoning, 2009. In: INTERNATIONAL JOINT CONFERENCE ON ARTIFICIAL INTELLIGENCE, 21, 2009b. Pasadena. Comunicação oral.

WALTON, Douglas. On a razor's edge: Evaluating arguments from expert opinion. Argument \& computation, Cambridge, v. 5, n. 2-3, p. 139-159, 2014a.

WALTON, Douglas; MACAGNO, Fabrício. Reasoning from classifications and definitions. Argumentation, Dordrecht, v. 23, n. 1, p. 81-107, 2009.

WALTON, Douglas; MACAGNO, Fabrício. The importance and trickiness of definition strategies in legal and political argumentation journal of politics and law, Journal of Politics and Law, Ontário, v. 8, n. 1, p. 137-148, 2015.

WALTON, Douglas; REED, Chris.; MACAGNO, Fabrício. Argumentation schemes. Cambridge: Cambridge University Press, 2008.

WENZEL, Joseph. W. Three perspectives on argument: rhetoric, dialectic, logic. In: TRAPP, Robert; SCHUETZ, Janice (Ed.). Perspectives of argumentation: Essays in honour of Wayne Brockriede. New York: Waveland, 1990. p. 9-26.

ZEMBAUL-SAUL, Carla; MUNFORD, Danuza; CRAWFORD, Barbára; FRIEDRICHSEN, Patrícia ; LAND, Susan. Scaffolding Preservice Science Teachers' Evidence-Based Arguments During and Investigation of Natural Selection. Research in Science Education, Dordrecht, v. 32, n. 4, p. 437-463, 2002.

ZOHAR, Anet; NEMET, Flora. Fostering student's knowledge and argumentation skills through dilemas in human genetics. Journal of Research in Science Teaching, Hoboken, v. 39, n. 1, p. 35-62, 2002. 
Data de recebimento: 29/10/2015

Data de aprovação: 01/06/2016

Data da versão final: $05 / 07 / 2016$

Contato:

Marina Martins

Universidade Federal de Minas Gerais

Faculdade de Educação

Avenida Antonio Carlos, 6627 - Campus Pampulha

Belo Horizonte, MG - Brasil

CEP: $31.270-901$

marina.r.martins87@gmail.com

\section{ERRATA}

No Resumen do artigo Esquemas argumentativos de Walton na análise de argumentos de professores de química em formação inicial, com número de DOI: http://dx.doi.org/10.1590/1983-21172016180203, publicado em Ahead of print, Epub 18-Jul-2016, referente ao periódico Revista Ensaio vol.18 nº.2, Belo Horizonte, mai./ago. 2016: < http://www.scielo.br/scielo.php?script=sci_ abstract\&pid=S198321172016005002102\&lng=pt\&nrm=iso\&tlng=es $>$, na página 1,

onde se lia:

“RESUMEN: Utilizamos los 60 Esquemas Argumentativos de Walton (EAW) para analizar, reconstruir y clasificar argumentos de profesoras de química en formación inicial en situación de entrevista acerca dos problemas: i) derretimiento de muñecos de nieve (SP1); ii) la queima de una vela (SP2). Ambos favorecen la movilización de argumentos que usan conceptos científicos, en SP1 el cámbio de estado físico y fenómenos de absorción de luz y en SP2 reacciones químicas. Cada problema demandava de los sujetos habilidades distintas para análisis de evidéncias, proposición de justificativas y elaboración de conclusiones. Hubo predomínio de esquemas relaccionados al raciocínio científico - qué indica que las licensiadas manifestaron tal forma de pensar, algo relevante para el aula $-\mathrm{y}$ número similar de argumentos en los dos problemas. Percibimos que los tipos de EAW movilizados por las licensiadas fueron influenciados por la naturaleza de los problemas ypor los conocimientos científicos de las resoluciones."

\section{leia-se:}

"RESUMEN: Utilizamos los 60 Esquemas Argumentativos de Walton (EAW) para analizar, reconstruir y clasificar argumentos de profesoras de química en formación inicial en situación de entrevista acerca dos problemas: i) derretimiento de muñecos de nieve (SP1); ii) la queima de una vela (SP2). Ambos favorecen la movilización de argumentos que usan conceptos científicos: en SP1 el cámbio de estado físico y fenómenos de absorción de luz y en SP2 reacciones químicas. Cada 
problema demandava de los sujetos habilidades distintas para análisis de evidéncias, proposición de justificativas y elaboración de conclusiones. Hubo predomínio de esquemas relaccionados al raciocínio científico - qué indica que las licenciadas manifestaron tal forma de pensar, algo relevante para el aula - y número similar de argumentos en los dos problemas. Percibimos que los tipos de EAW movilizados por las licenciadas fueron influenciados por la naturaleza de los problemas y por los conocimientos científicos de las resoluciones."

No Abstract do artigo Esquemas argumentativos de Walton na análise de argumentos de professores de química em formação inicial, com número de DOI: http://dx.doi.org/10.1590/1983-21172016180203, publicado em Ahead of print referente ao periódico Revista Ensaio. vol.18 no.2, Belo Horizonte, mai./ago. 2016: < http://www.scielo.br/scielo.php?script=sci_ abstract\&pid $=$ S198321172016005002102\&lng=pt\&nrm=iso\&tlng=en $>$, na página 2,

onde se lia:

“ABSTRACT: We used Walton's 60 Argumentative Schemes (WAS) to analyse preservice chemistry teacher's arguments in an interview about two problems: i) snowmen melting (SP1); and ii) a burning candle (SP2). The problems have issues that support the mobilization of arguments involving scientific concepts' use. SP1 favours knowledge related to physical state changes and absorption and reflection of light, while SP2 involves chemical reactions. Given the specificities of each problem, the problems demanded distinct skills from the pre-service chemistry teachers, regarding the analysis of evidence, proposing justifications and drawing conclusions. The arguments were delimited, their definitions were rewritten, and they were classified based on WAS. We found a predominance of schemes related to scientific reasoning and similar arguments in the two problems. The predominance of the WAS related to thoughts inherent to scientific reasoning indicates that teachers had developed such ways of thinking, which may be relevant to classroom situations. We realised that the WAS kinds mobilized by the pre-service teachers are influenced by the nature of the problems and the scientific knowledge involved in the resolutions."

\section{leia-se:}

“ABSTRACT: We used Walton's 60 Argumentative Schemes (WAS) to analyse preservice chemistry teacher's arguments in an interview about two problems: i) snowmen melting (SP1); and ii) a burning candle (SP2). Both problems favour arguments mobilization involving scientific concepts' use. SP1 favours knowledge related to physical state changes and absorption and reflection of light, while SP2 involves chemical reactions. The problems demanded distinct skills from the pre-service chemistry teachers, regarding the analysis of evidence, proposing justifications and drawing conclusions. We found a predominance of schemes related to scientific reasoning and similar arguments in the two problems - which indicates that teachers had developed such ways of thinking, which may be relevant to classroom situations. We realised that the WAS kinds mobilized by the pre-service teachers are influenced by the nature of the problems and the scientific knowledge involved in the resolutions." 